\title{
Mass media exposure, social stratification, and tobacco consumption among Nigerian adults
}

\section{Citation}

Tafawa, Adebola Odunlami, Kasisomayajula Viswanath, Ichiro Kawachi, and David R. Williams. 2012. "Mass Media Exposure, Social Stratification, and Tobacco Consumption among Nigerian Adults." Cancer Causes \& Control 23 (S1): 45-55. https://doi.org/10.1007/s10552-012-9898-9.

\section{Permanent link}

http://nrs.harvard.edu/urn-3:HUL.InstRepos:41275519

\section{Terms of Use}

This article was downloaded from Harvard University's DASH repository, WARNING: This file should NOT have been available for downloading from Harvard University's DASH repository.

\section{Share Your Story}

The Harvard community has made this article openly available.

Please share how this access benefits you. Submit a story.

\section{Accessibility}




\title{
Mass media exposure, social stratification, and tobacco consumption among Nigerian adults
}

\author{
Adebola Odunlami Tafawa $\cdot$ Kasisomayajula Viswanath • \\ Ichiro Kawachi $\cdot$ David R. Williams
}

Received: 8 July 2011/ Accepted: 21 January 2012/Published online: 15 February 2012

(C) Springer Science+Business Media B.V. 2012

\begin{abstract}
Background Mass media exposure is a strong determinant of tobacco use yet little is known about this relationship in African countries. We explored socio-demographic and socio-contextual correlates of tobacco consumption and associations between mass media exposure, gender and the use of any and various forms of tobacco among Nigerians. Methods The study included 47,805 adults from the crosssectional and nationally representative Nigeria demographic and health survey 2008. Weighted binary logistic models predicted any tobacco use whereas weighted multinomial logistic models predicted smoking and smokeless tobacco, all compared with no tobacco use.

Results Approximately $4.2 \%$ of Nigerian adults used tobacco-2.7\% smoked tobacco whereas $1.5 \%$ used smokeless tobacco. Tobacco use was more prevalent among men than women $(12 \%$ vs. $0.6 \%$; $p$ value $<0.0001)$. Gender modified the associations between tobacco use and radio exposure or TV exposure ( $p$ values ranged $=0.02-0.05$ ). Among men, some radio exposure and high radio exposure were associated with increased odds of any tobacco use, compared with no radio exposure. Among men, infrequently reading newspapers/magazines and frequently reading newspapers/magazines were associated with higher odds of smokeless tobacco use, compared with not reading newspapers/magazines. Among women, infrequently reading newspapers/magazines was associated with reduced odds of
\end{abstract}

A. O. Tafawa · K. Viswanath · I. Kawachi · D. R. Williams Department of Society, Human Development, and Health, Harvard School of Public Health, Boston, MA, USA

A. O. Tafawa $(\square)$

387 Franklin Avenue, Suite 102, 53 Breakwater Drive, Chelsea, MA 02150, USA

e-mail: Bola.Tafawa@gmail.com smokeless tobacco use, compared with not reading newspaper/magazines.

Conclusions The relationships between mass media exposure and tobacco consumption differed by gender and were more pronounced among men. Research on radio programs may help to form policies that can address tobacco use among Nigerian men.

Keywords Tobacco $\cdot$ Mass media $\cdot$ Nigeria $\cdot$ Africa . Socio-economic status

\section{Introduction}

Global tobacco consumption is on the rise. By 2020, $70 \%$ of smoking-related deaths worldwide will be in developing countries [1, 2]. Between 1995 and 2000, cigarette consumption in Sub-Saharan Africa increased by $38.4 \%$ [3]. This increased tobacco consumption is associated with increased presence and marketing strategies of tobacco companies in several low and middle income countries, including Nigeria [1]. With over 158 million inhabitants, Nigeria is Africa's most populous country, accounting for $47 \%$ of the population in West Africa [4, 5]. Given its size, Nigeria is a logical target for tobacco companies, especially British American Tobacco Company (BAT), which controls over $92 \%$ of the market in Nigeria. Insights from BAT's internal documents, made publically available with litigations against them, offer comparisons between their marketing and advertising tactics, and empirical research on tobacco use and associated policies [3]. As an example, anticipating marketing restrictions such as Nigeria's ratification of the World Health Organization's framework convention on tobacco control (WHO FCTC), BAT recognized that alternative marketing and advertising tactics, 
for example music sponsorship at concerts and campuses can be used "even when cigarette advertising and promotion are further restricted" [6, 7]. However, while BAT documents associations between exposure to mass media and tobacco use [8], there is a dearth of empirical research that examines the role of media exposure on tobacco use among Nigerians. In this paper we investigate the relationships between exposure to mass media and tobacco use in Nigeria while documenting socio-economic correlates of tobacco use. This research can help supplement surveillance activities and help to form policies that seek to restrict tobacco marketing activities in Nigeria.

Mass media exposure is a significant predictor of favorable attitudes and even experimentation with tobacco [9]. Most empirical work, albeit focused on young mass media consumers in developed countries, has concluded that advertising and placement of tobacco products in the media normalize tobacco consumption, increase the social acceptability of smoking, and reinforce tobacco use $[9,10]$. Entertainment media outlets, for example television, movies, and radio are influential in initiating or sustaining the smoking habits of consumers $[9,11]$. In low and middle income countries, emerging studies on mass media exposure report a positive association with tobacco use. In Ghana, smoking prevalence was higher in households that owned a television or radio, compared with those that owned a telephone or car [12]. In South Africa, exposure to cigarette advertising, mainly through radio advertisements and "giveaways" of tobacco paraphernalia, was associated with more favorable tobacco attitudes among adult women [13]. Favorable attitudes towards tobacco were associated with smoking among school-age youth in India and mediated the relationship between increased exposure to Western media and smoking among Egyptian adolescents $[14,15]$. Tobacco industry documents corroborate these findings as they indicate segmenting of entertainment media and advertising through channels that target specific audiences [16]. Importantly, BAT believes music can transcend the "barriers to communication imposed by limited literacy or language difficulties" and have used print, television, and radio media campaigns, for example "golden tones" and "turn to gold", to target men [17-19].

Related to segmented advertising, gender norms may underlie different smoking behavior and help explain the potentially different effect of mass media exposure on tobacco use across gender. In low and middle income countries, prevalence of tobacco use is greater among men than among women $[20,21]$. The few reports on tobacco use in Nigeria document prevalence that is significantly higher for men than for their female counterparts [22]. The few studies on gender norms and smoking show that in South Africa and Egypt smoking tobacco is regarded as a cultural taboo for women and qualitative data suggest that women smokers are thought to be "disrespectful" and "manly" $[13,14]$. The few female tobacco users are more likely to use the more discrete smokeless tobacco [23]. Notably, most of BAT's advertisements have focused on cigarettes, which are mostly used by men [19]. The segmented targeting of tobacco advertising and access to tobacco products suggests that gender modifies the association between mass media exposure and tobacco use. As an example, in Ghana, tobacco is sold in drinking pubs and clubs, which are more often associated with music, and more frequented by men, rather than the grocery stores and shops that women frequent [12].

To address segmented advertisements, Nigeria ratified WHO's FCTC in 2005 but has yet to implement the laws recommended by the FCTC [24]. Before 2005, laws that banned tobacco advertising on television and radio, and in newspapers and magazines were in place in one state only [24]. As such, tobacco advertisements across billboards and sponsorship of music programs have been widely available in different Nigerian settings [24, 25]. The partial ban on tobacco product advertising (which excludes advertising of tobacco services, for example concerts), voluntarily placed in 2002 by Advertising Practitioners Promotion Control of Nigeria, has been largely ineffective given that some of its members still illegally support tobacco advertising [26]. To regulate advertising, in 2009, the Nigerian Ministry of Health presented a national tobacco control bill intended to replace the 1990 anti-Tobacco Act and address all the FCTC recommendations. The national tobacco control bill, if enacted, will prohibit all advertising, promotion, and sponsorship of tobacco products, ban sales of single cigarettes, prohibit public smoking, and require tobacco companies to include pictorial warnings on cigarette packets [27]. Nationally representative data on tobacco use will be helpful to assess the effectiveness of this important health policy. To this end, our objective was to describe the sociodemographic and socio-contextual correlates of tobacco consumption, assess the different associations between media exposure and tobacco use across gender, and investigate the relationships between media exposure and use of various forms of tobacco among Nigerian adults.

\section{Methods}

\section{Data source}

This study utilized data from the 2008 Nigeria demographic and health survey (NDHS 2008) [5]. NDHS 2008 is a cross-sectional survey that uses a stratified two-stage cluster design to collect data on various maternal and child health indicators, including tobacco use, among Nigerian adults. The 2006 Population and Housing Census of the 
Federal Republic of Nigeria served as the NDHS 2008 sampling frame. Enumeration areas that provided 888 clusters were stratified by urban and rural areas to allow oversampling of urban areas before selection of households. All women, ages 15-49, who were either permanent residents or overnight visitors in all selected households and all males, ages 15-59, who were either permanent residents or overnight visitors in half of the selected households were eligible to participate. A final representative sample of 36,298 households was selected for the 2008 NDHS sample with 34,070 successfully interviewed households to yield a $98.3 \%$ response. In these households, 34,596 women were eligible for the individual interview and of these 33,385 completed the interviews to yield a response of $96.5 \%$. Similarly, of the 16,722 eligible men identified, 15,486 completed the interview to yield a response of $98.4 \%$. Before conducting the individual interviews, the NDHS survey interviewers were required to undertake three-week pre-test training in the three major Nigerian languages (Hausa, Igbo, and Yoruba). In addition to English, the NDHS questionnaire was translated into the three major Nigerian Languages.

\section{Variables}

Two NDHS 2008 questionnaires (males and females) were merged to create the dataset for this study. The male questionnaire had the same information as the female questionnaire except that the latter asked additional questions about reproductive and maternal and child health. From the merged dataset, the outcome variables included, use of smoking tobacco (cigarette, pipe or other), use of smokeless tobacco (chewing or snuff), and both combined as any tobacco use. These variables were created from responses to questions:

1 "Do you currently smoke or use any other type of tobacco?" (yes or no); and

2 If yes, "what (other) type of tobacco do you currently smoke or use, apart from cigarettes?" Response options were pipe, chewing tobacco, snuff or other.

One-hundred and thirty-three individuals used more than one form of tobacco (e.g. cigarette smoking and snuff) but were included as single users of tobacco. Exposure to the media outlets radio, newspaper/magazine, or television were created from responses to the questions:

1 "do you read a newspaper or magazine almost every day, at least once a week, less than once a week, or not at all?";

2 "do you listen to the radio almost every day, at least once a week, less than once a week, or not at all?"; and

3 "do you watch television almost every day, at least once a week, less than once a week, or not at all?"
The responses were then categorized as no exposure (not at all), some exposure (less than once a week), or high exposure (at least once a week or almost every day) for each type of media channel. Educational attainment was assessed on the basis of "have you ever attended school" and "what is the highest level of school you attended" with responses categorized as never attended school, primary, secondary, or higher. Responses to "have you done any work in the last 12 months?" were dichotomized to provide information about current employment status. Marital status was assessed from responses to "are you currently married or living together with a man as if married?" or "have you ever been married or lived together with a man as if married?" or "what is your marital status now: are you widowed, divorced or separated?"). Three categories were used to classify responses: currently married, formerly married, and never married. Ethnicity was assessed by asking "what is your ethnic group?" and responses were coded into one of four categories (Yoruba, Igbo, Hausa, or other ethnicity). Religion was assessed with "what is your religion?" and responses were classified as Catholic, other Christian, Muslim, or other (Traditionalist or other religion). For urbanicity, interviewers indicated whether the household was in an urban or rural area. Consistent with similar studies, a household wealth/standard of living measure was developed from questions on the ownership of household durable goods, dwelling characteristics, type of sanitation, and type of material used for flooring [5]. Each asset from the list was assigned a weight from principalcomponents analysis and then standardized. The final summed asset score was divided into quintiles [5]. Harvard School of Public Health Institutional Review Board provided ethical approval for this study.

Data analysis

SAS version 9.2 was used to analyze cross tabulations and weighted regression models. All relationships were assessed for significance at an alpha level of $p<0.05$. Patterns of missing data across key predictors were examined, concluded as not systematic, and cases with missing data were deleted $(4.05 \%$ of total data). Basic descriptive analyses examined the weighted distribution of outcomes across independent variables and their associated $\chi^{2}$ tests. The low prevalence of the outcomes in this population $(<10 \%)$ resulted in the use of odds ratio [28]. All variables in the regression analyses were categorical using dummycoded categories. Additionally, weights were included in bivariate and multivariable analysis to adjust for clustering and inverse probability of selection of individuals such that the findings reflect the estimated population relationships.

Binary logistic regression models analyzed the association between predictors and any tobacco use. First, we 
included cross-product interaction terms for gender and exposure to radio and exposure to television to assess gender as a modifier of the association between mass media exposure and tobacco use in models that also included the main effect terms for all three media exposure variables and the demographic variables age, marital status, education, employment status, wealth, ethnicity, religion, and urbanicity. The interaction terms associated with newspaper/magazine exposure and gender were excluded from the model because tobacco use and reading newspaper/magazine did not vary by gender-only five women used any tobacco and also read any newspaper/magazine. Gender modified the association between media exposure and any tobacco use so we built separate regression models for men and women. Second, we used all media exposure variables to predict any tobacco use, compared with no tobacco use, while adjusting for demographic variables of age and marital status (model 1a). Third, socio-economic variables of education, employment status and wealth were added to the model (model 1b). Finally, social contextual variables of ethnicity, religion and urbanicity were added, (model 1c). Weighted multinomial logistic regression models (MLM) assessed the associations between predictors and three events: smoking tobacco (models 2a-2c), smokeless tobacco use (models 3a-3c), and no tobacco use (reference group). Separate analyses by gender using MLM models, were built similarly to the logistic regression models: first model predicted outcomes with media exposure while adjusting for age and marital status, second model further adjusted for social economic variables, and the final model further adjusted for social contextual variables.

\section{Results}

As detailed in Table 1, 32\% of our sample were male, 54\% were age 29 or younger, and half belonged to one of the top three ethnic groups in Nigeria (Hausa, Igbo, Yoruba). An estimated $4.2 \%$ of the sample used tobacco- $2.7 \%$ smoked tobacco and $1.5 \%$ used smokeless tobacco. Prevalence of tobacco use remained the same among adults: when 5,284 individuals under age 18 were deleted, $4.75 \%$ of the adult sample used tobacco, $3.06 \%$ smoking and $1.68 \%$ smokeless. The distribution of any tobacco use and smoking tobacco significantly varied across exposure levels to radio, newspapers/magazines, and television (all $p$ values $<0.01$ ). Across exposure levels, those with high exposure to radio or newspaper/magazines had the highest prevalence of using any tobacco or smoking tobacco whereas individuals with some exposure to television had the highest prevalence level of using any tobacco or smoking tobacco. Any tobacco use was more prevalent among men than women (12\% vs. $0.6 \% ; p$ value $<0.0001)$. Men had a higher prevalence of any tobacco use, smoking tobacco, and smokeless tobacco than women $(p$ value $<0.0001$ ). The highest prevalence of all forms of tobacco use was associated with increased age, having primary education, being formerly married, being unemployed, being Igbo, and being Muslim.

All four two-way interaction terms for gender and (some or high) exposure to radio and gender and (some or high) exposure to TV were significant ( $p$ values ranged from 0.02 to 0.05 ) indicating that gender modified the association between radio exposure or TV exposure and any tobacco use after we controlled for other variables. Across models that adjusted for socio-demographic and socio-contextual variables, the only statistically significant predictor of any tobacco use was radio exposure (Fig. 1). In fully adjusted models that controlled for all socio-demographic and socio-contextual variables, among men, some radio exposure was associated with $30 \%$ increased odds of any tobacco (95\% CI 1.0-1.6) and high radio exposure was associated with a $20 \%$ increased odds of any tobacco use, both compared with no radio exposure (95\% CI 1.0-1.5) (Table 2, model 1c). Similarly, in fully adjusted models (model 2c), both some and high radio exposure were associated with a $40 \%$ increased odds of smoking tobacco (95\% CI 1.1-1.9 and 1.0-1.7), both compared with no radio exposure. In fully adjusted models, exposure to newspaper/magazine was a determinant of tobacco use among men. Compared with men that do not read newspapers/magazines, men that infrequently read newspapers/ magazines (some exposure) had 20\% decreased odds of using any tobacco (95\% CI $0.7-1.0)$ and $30 \%$ decreased odds of using smokeless tobacco (95\% CI 0.5-1.0). Compared with men that do not read newspapers/magazines, men that frequently read newspapers/magazines (high exposure) had 30\% decreased odds of using any tobacco (95\% CI $0.6-0.8$ ), 30\% decreased odds of smoking (95\% CI 0.6-0.9), and 30\% decreased odds of using smokeless tobacco (95\% CI 0.5-0.9). Among women, reading magazines/newspapers infrequently (some exposure) was the only statistically significant predictor of tobacco use (Table 3). In fully adjusted models, women that read newspapers/magazines infrequently had $80 \%$ decreased odds of using any tobacco (95\% CI $0.0-0.8$ ), compared to their counterparts that do not read newspapers/magazines. This effect is robust with narrow confidence intervals even with the limited power that the small sample allows.

\section{Discussion}

As far as we are aware, this is the first study to use nationally representative data, from all 36 Nigerian states and the federal capital territory, and a robust analytical 
Table 1 Prevalence of any tobacco use, smoking tobacco, and smokeless tobacco use among Nigerian adults $(n=47,085)$

\begin{tabular}{|c|c|c|c|c|}
\hline Variable & $\begin{array}{l}\text { Unweighted sample } \\
\text { size }(\%)\end{array}$ & $\begin{array}{l}\text { Any tobacco use } \\
\text { weighted }(\%)\end{array}$ & $\begin{array}{l}\text { Smoking tobacco } \\
\text { weighted }(\%)\end{array}$ & $\begin{array}{l}\text { Smokeless tobacco } \\
\text { weighted }(\%)\end{array}$ \\
\hline Prevalence $(95 \% \mathrm{CI})$ & $47,085(100)$ & 4.2 & 2.7 & 1.5 \\
\hline \multicolumn{5}{|l|}{ Radio } \\
\hline No exposure & $12,812(26.9)$ & $2.4(1.9-2.9)$ & $1.0(0.8-1.3)$ & $1.4(1.0-1.8)$ \\
\hline Low exposure & $6,336(13.3)$ & $3.1(2.6-3.7)$ & $1.9(1.5-2.4)$ & $1.2(0.9-1.5)$ \\
\hline High exposure & $28,434(59.8)$ & $5.2(4.7-5.6)$ & $3.5(3.2-3.8)$ & $1.6(1.4-1.9)$ \\
\hline$\chi^{2} / d f_{2}$ & & $<.0001$ & $<.0001$ & 0.1182 \\
\hline \multicolumn{5}{|l|}{ Magazines } \\
\hline No exposure & 34,049 (71.6) & $3.9(3.5-4.3)$ & $2.3(2.0-2.5)$ & $1.6(1.4-1.9)$ \\
\hline Low exposure & $6,052(12.7)$ & $4.8(4.2-5.5)$ & $3.5(3.0-4.0)$ & $1.3(1.0-1.7)$ \\
\hline High exposure & $7,481(15.7)$ & $5.0(4.4-5.7)$ & $3.8(3.3-4.4)$ & $1.2(0.9-1.5)$ \\
\hline$\chi^{2} / d f_{2}$ & & $<.0003$ & $<.0001$ & 0.0479 \\
\hline \multicolumn{5}{|l|}{ TV } \\
\hline No exposure & $23,077(48.5)$ & $4.0(3.5-4.5)$ & $2.1(1.9-2.4)$ & $1.9(1.5-2.3)$ \\
\hline Low exposure & $5,899(12.4)$ & $5.3(4.5-6.1)$ & $3.5(2.9-4.1)$ & $1.8(1.4-2.2)$ \\
\hline High exposure & $18,606(39.1)$ & $4.1(3.7-4.5)$ & $3.1(2.8-3.4)$ & $1.0(0.9-1.2)$ \\
\hline$\chi^{2} / d f_{2}$ & & 0.0071 & $<.0001$ & $<.0001$ \\
\hline \multicolumn{5}{|l|}{ Gender } \\
\hline Males & 15,177 (31.9) & $12.0(11.1-12.8)$ & $8.2(7.6-8.9)$ & $3.76(3.3-4.3)$ \\
\hline Females & $32,405(68.1)$ & $0.6(0.4-0.8)$ & $0.1(0.1-0.2)$ & $0.46(0.3-0.6)$ \\
\hline$\chi^{2} / d f_{1}$ & & $<.0001$ & $<.0001$ & $<.0001$ \\
\hline \multicolumn{5}{|l|}{ Age } \\
\hline $15-29$ & $25,739(54.1)$ & $2.3(12.0-2.5)$ & $1.7(1.5-1.9)$ & $0.6(0.4-0.7)$ \\
\hline $30-39$ & $11,957(25.1)$ & $4.9(14.4-5.4)$ & $3.5(3.1-3.9)$ & $1.4(1.1-1.7)$ \\
\hline $40-59$ & $9,886(20.8)$ & $8.5(7.7-9.3)$ & $4.5(3.9-5.0)$ & $4.1(3.5-4.7)$ \\
\hline$\chi^{2} / d f_{2}$ & & $<.0001$ & $<.0001$ & $<.0001$ \\
\hline \multicolumn{5}{|l|}{ Marital status } \\
\hline Never married & $14,132(29.7)$ & $3.2(2.8-3.5)$ & $2.5(2.2-2.6)$ & $0.6(0.5-0.8)$ \\
\hline Currently married & $31,785(66.8)$ & $4.6(4.2-5.0)$ & $2.7(2.5-3.0)$ & $1.8(1.6-2.1)$ \\
\hline Formerly married & $1,665(3.5)$ & $7.0(5.6-8.4)$ & $4.0(2.9-5.0)$ & $3.0(2.0-4.1)$ \\
\hline$\chi^{2} / d f_{2}$ & & $<.0001$ & 0.0118 & $<.0001$ \\
\hline \multicolumn{5}{|l|}{ Education } \\
\hline No education & $16,355(34.4)$ & $3.3(2.7-3.9)$ & $1.6(1.4-1.9)$ & $1.7(1.2-2.1)$ \\
\hline Primary & $9,592(20.2)$ & $7.0(6.3-7.2)$ & $4.1(3.6-4.6)$ & $2.9(2.5-3.4)$ \\
\hline Secondary & $17,000(35.7)$ & $3.6(3.3-4.0)$ & $2.8(2.5-3.1)$ & $0.9(0.7-1.0)$ \\
\hline Higher & 4,635 (9.7) & $3.9(3.3-4.5)$ & $3.1(2.6-3.7)$ & $0.8(0.5-1.0)$ \\
\hline$\chi^{2} / d f_{3}$ & & $<.0001$ & $<.0001$ & $<.0001$ \\
\hline \multicolumn{5}{|l|}{ Current employment } \\
\hline Employed & $15,954(33.5)$ & $0.8(0.6-1.0)$ & $0.6(0.4-0.7)$ & $0.2(0.1-0.3)$ \\
\hline Unemployed & $31,628(66.5)$ & $5.9(5.5-6.4)$ & $3.8(3.5-4.1)$ & $2.2(1.9-2.5)$ \\
\hline$\chi^{2} / d f_{1}$ & & $<.0001$ & $<.0001$ & $<.0001$ \\
\hline \multicolumn{5}{|l|}{ Wealth } \\
\hline Lowest & $10,076(21.2)$ & $4.8(3.9-5.8)$ & $2.6(2.0-3.1)$ & $2.3(1.6-3.0)$ \\
\hline Second & $9,408(19.8)$ & $4.3(3.6-4.9)$ & $2.4(2.0-2.8)$ & $1.9(1.4-2.3)$ \\
\hline Middle & $9,438(19.8)$ & $4.9(4.4-5.5)$ & $3.0(2.6-3.4)$ & $1.9(1.6-2.3)$ \\
\hline Fourth & $9,637(20.3)$ & $4.3(3.8-4.8)$ & $3.1(2.7-3.5)$ & $1.2(0.9-1.4)$ \\
\hline Highest & $9,023(19.0)$ & $3.1(2.7-3.6)$ & $2.5(2.1-2.9)$ & $0.6(0.4-0.8)$ \\
\hline$\chi^{2} / d f_{4}$ & & 0.0011 & 0.0468 & $<.0001$ \\
\hline
\end{tabular}


Table 1 continued

\begin{tabular}{|c|c|c|c|c|}
\hline Variable & $\begin{array}{l}\text { Unweighted sample } \\
\text { size }(\%)\end{array}$ & $\begin{array}{l}\text { Any tobacco use } \\
\text { weighted }(\%)\end{array}$ & $\begin{array}{l}\text { Smoking tobacco } \\
\text { weighted }(\%)\end{array}$ & $\begin{array}{l}\text { Smokeless tobacco } \\
\text { weighted }(\%)\end{array}$ \\
\hline \multicolumn{5}{|l|}{ Ethnicity } \\
\hline Hausa & $10,103(21.2)$ & $2.8(2.3-3.2)$ & $2.0(1.6-2.4)$ & $0.7(0.5-1.0)$ \\
\hline Igbo & $6,388(13.4)$ & $6.7(5.9-7.5)$ & $3.3(2.8-3.8)$ & $3.4(2.7-4.1)$ \\
\hline Yoruba & $7,172(15.1)$ & $2.8(2.4-3.3)$ & $2.2(1.8-2.6)$ & $0.6(0.4-0.9)$ \\
\hline Other & $23,919(50.3)$ & $4.8(4.1-5.2)$ & $3.1(2.7-3.4)$ & $1.6(1.2-2.0)$ \\
\hline$\chi^{2} / d f_{3}$ & & $<.0001$ & $<.0001$ & $<.0001$ \\
\hline \multicolumn{5}{|l|}{ Religion } \\
\hline Catholic & 5,134 (11.6) & $8.0(6.8-9.0)$ & $4.3(2.5-5.0)$ & $3.7(2.9-4.5)$ \\
\hline Other Christian & $19,487(42.3)$ & $2.8(2.5-3.2)$ & $1.9(1.7-2.2)$ & $0.9(0.7-1.1)$ \\
\hline Muslim & 22,123 (44.6) & $19.2(14.4-24.1)$ & $8.2(5.8-10.6)$ & $11.0(6.6-15.5)$ \\
\hline Other & $838(1.5)$ & $4.1(3.8-4.5)$ & $2.9(2.6-3.2)$ & $1.2(1.0-1.4)$ \\
\hline$\chi^{2} / d f_{3}$ & & $<.0001$ & $<.0001$ & $<.0001$ \\
\hline \multicolumn{5}{|l|}{ Residence } \\
\hline Urban & $15,229(32.0)$ & $3.8(3.4-4.3)$ & $2.8(2.4-3.1)$ & $1.0(0.8-1.3)$ \\
\hline Rural & $32,353(68.0)$ & $4.5(4.0-4.9)$ & $2.7(2.4-3.0)$ & $1.8(1.5-2.1)$ \\
\hline$\chi^{2} / d f_{1}$ & & 0.0523 & 0.6839 & $<.0001$ \\
\hline
\end{tabular}

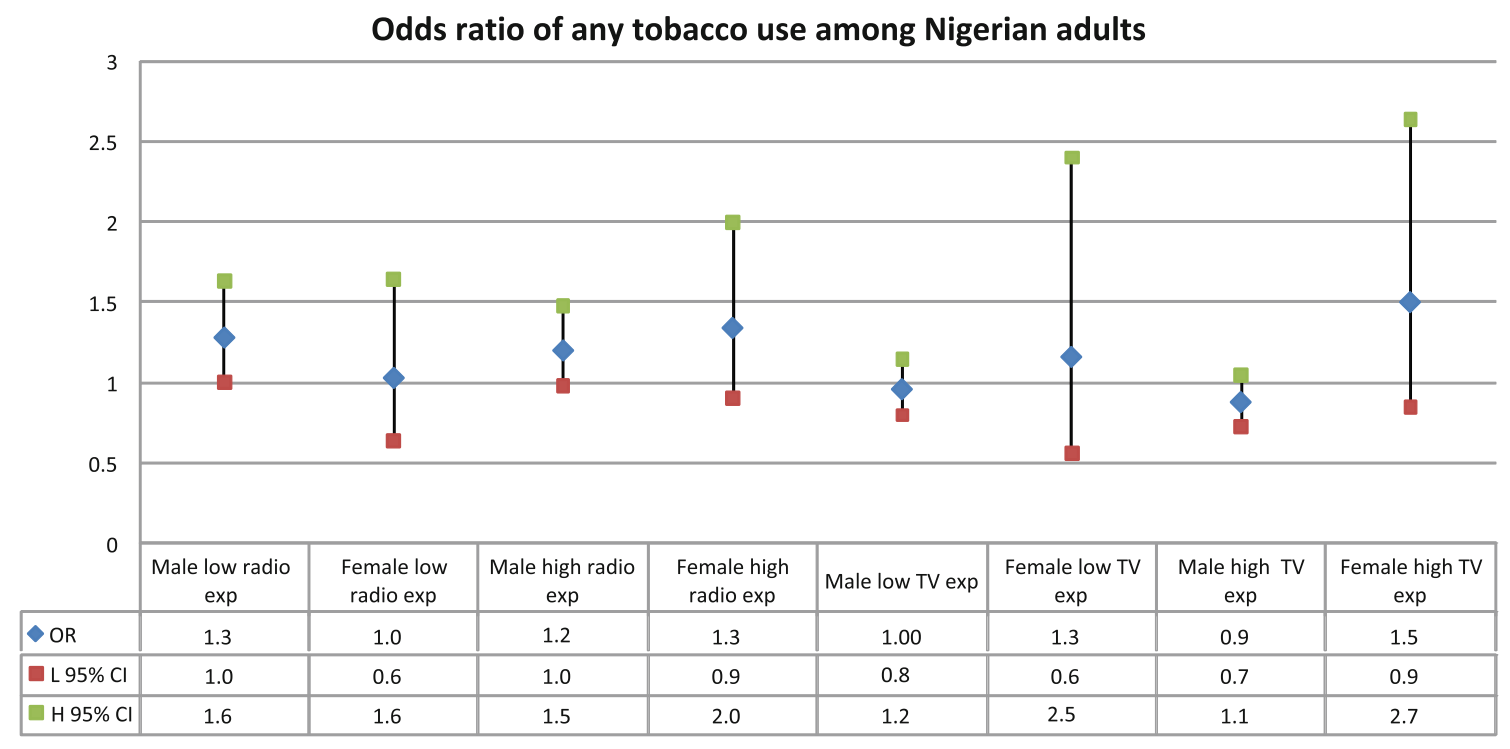

Fig. 1 Odds ratio of any tobacco use associated with media exposure across gender. All models adjusted for main effects of all the different types of mass media outlets and demographic, socio-economic, and

approach to assess the relationships between tobacco use and exposure to different mass media channels, among Nigerian adults. The low prevalence of tobacco use is consistent with previous (smaller) studies among Nigerian adults, including the World Health Organization's 2010 reports [29-31]. Our findings are consistent with reports of a higher prevalence of tobacco use among men compared with women in low and middle income countries and socio-contextual variables of age, marital status, education, employment status, wealth, ethnicity, religion, and urbanicity

indicative of an early tobacco epidemic [11, 12, 20, 22, 2934]. We provide evidence that the positive relationship between radio exposure and tobacco use and the negative relationship between newspaper/magazine exposure and tobacco use are robust among men, the primary users of tobacco in Nigeria. This finding is consistent with past reports of a positive relationship between exposure to radio and tobacco use in other African countries [14, 35]. This 


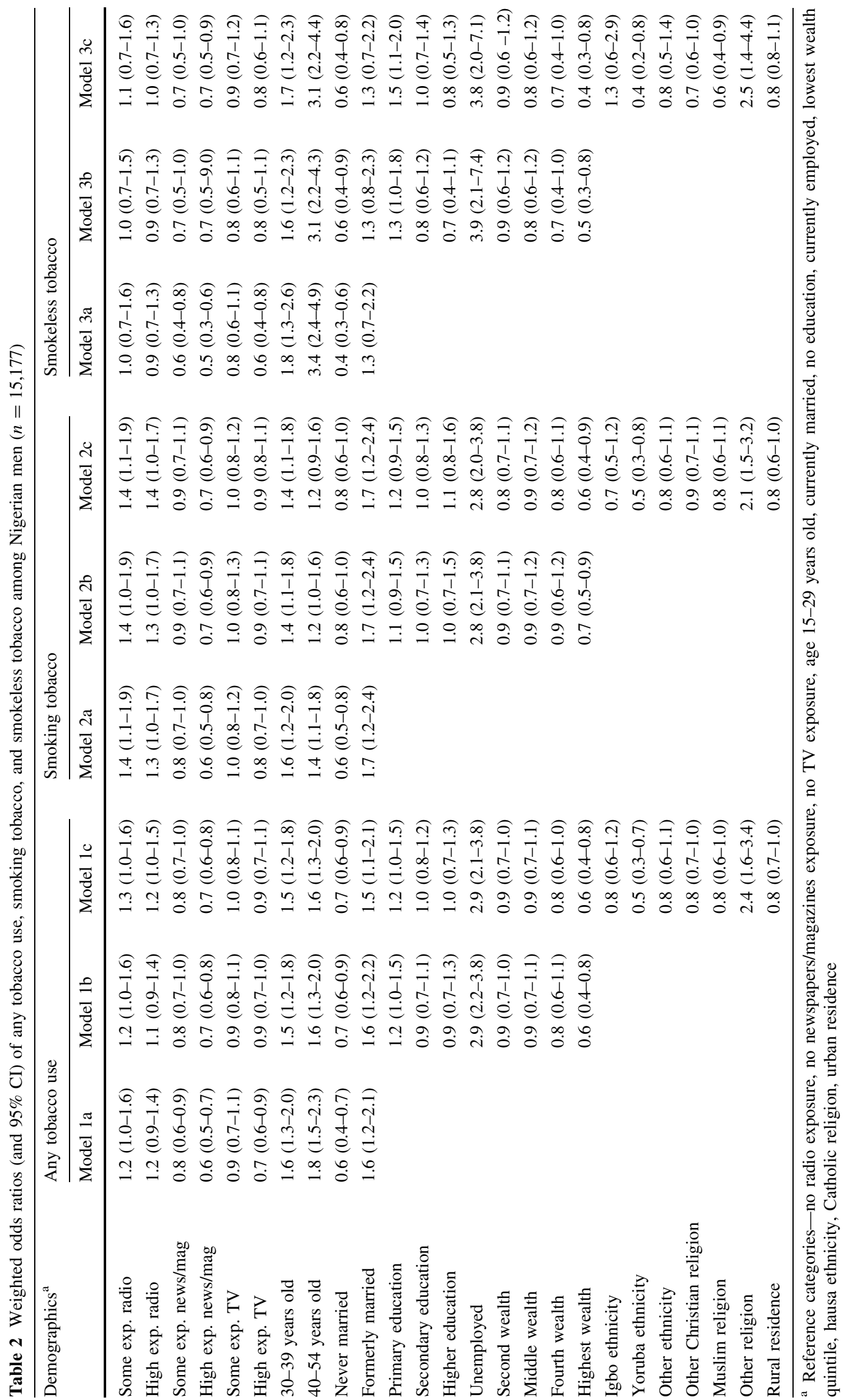




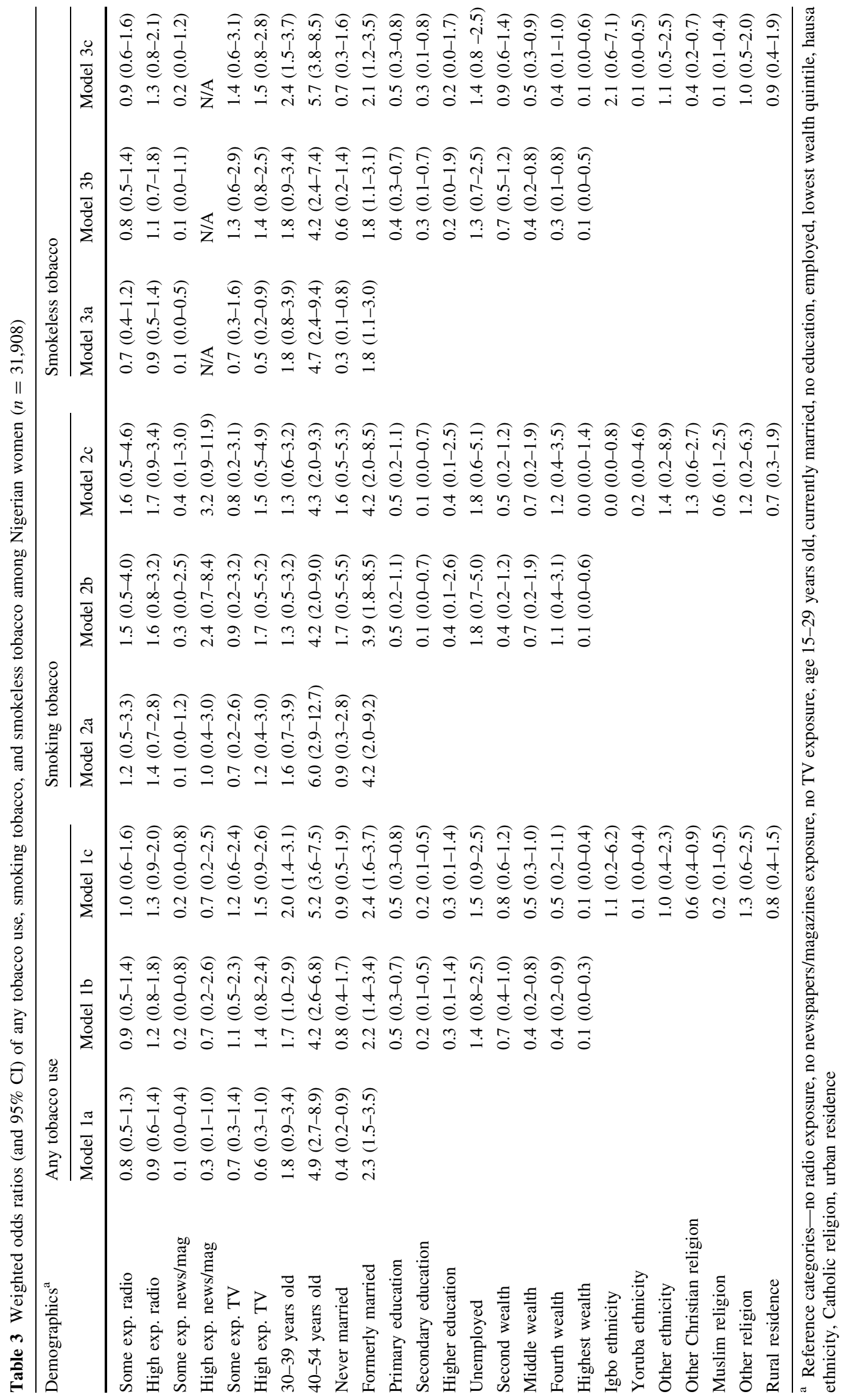


paper extends previous research by using a nationally representative dataset to investigate different types of mass media exposure as a determinant of tobacco use in this early stage of the tobacco epidemic in Nigeria.

Several factors may explain the presence of a positive relationship between radio exposure and tobacco use. Radio is the most prevalent form of mass media channel in Nigeria as more individuals use radio at least once weekly than any other medium. Specifically, $76 \%$ of the whole sample listened to radio at least once weekly. Although we were unable to directly assess specific types of radio programs patronized by Nigerian men, listening to music is unarguably a prevalent use of radio and may be an important pathway through which mass media exposure is associated with tobacco use. To target listeners, BAT has identified the use of radio and music sponsorship as an outlet that transcends educational levels and as such, uses tobacco-friendly messages that can be easily understood [18]. BAT also conducts their own concerts in Nigeria, under B\&H (Benson and Hedges) music, where they promote the music of several male artists. The paraphernalia distributed at these events are thought to provide reminders about various tobacco products that can then be associated with the radio messages. Although our data did not include questions specific to all advertising avenues such as listening to BAT-affiliated music, tobacco paraphernalia ownership, or participation in tobacco sponsorship activities, the evidence of a positive relationship between radio exposure and tobacco use, particularly smoking tobacco, is an important finding that future studies should explore. As expected, the positive association between radio exposure and smoking tobacco was more robust among men. Tobacco companies have identified men as targets for their promotional activities. In most low and middle income countries, women traditionally use money to cater for household needs whereas men are more likely to have the discretionary funds that enable tobacco use and are more likely to patronize concerts where pro-tobacco messages are constant which would result in higher message recall and product purchase [21].

Our failure to find a positive association between tobacco use and exposure to television may be attributed to several reasons. Perhaps, the most important is the difference in patterns of mass media use in Nigeria compared with the Western world where most of the positive associations between tobacco use and media exposure have been reported. As an example, there are differences in ownership of televisions in Nigeria and the US. In our nationally representative sample, $42 \%$ owned a television in their household whereas $56 \%$ watched TV at least once weekly, a stark comparison with the almost $80 \%$ that owned or listened to the radio at least once weekly. In the US, $82 \%$ of homes have more than one television, with the average household having 2.8 televisions $[9,36]$. Future studies on mass media and tobacco use need to mirror the patterns of media consumption in low and middle income countries by focusing on exposure to radio shows as a possible pathway that connects media exposure and tobacco use.

The inverse relationship between exposure to newspapers/magazines and tobacco use, driven by smokeless tobacco use, suggests several explanations. Our study used a single question to assess exposure to newspapers and magazines which may mask the true associations between these mass media outlets and tobacco use among Nigerian men. In Nigeria, men and women that read newspapers/ magazines and use smokeless tobacco are minorities. Reading newspapers/magazines and using smokeless tobacco may be an association better explained by a smaller yet comprehensive study that focuses on exploring associated pathways and underlying mechanisms. The work of several non-governmental organizations may also have attenuated the relationships between tobacco use and reading newspapers/magazines. Notably, similar to other low and middle income countries, Environmental Rights Action/Friends of the Earth Nigeria continue to counter pro-tobacco newspapers/magazines documents with their own anti-tobacco placements $[11,37]$. Stories of the short and long term negative effects of tobacco use are detailed in Nigerian newspapers and magazines particularly as some journalists serve as anti-tobacco advocates that have been personally affected by tobacco use [37].

Several associations between media exposure, tobacco use and other social-contextual factors exist but are beyond the scope of this paper. Meriting future studies, some evidence suggests religion and ethnicity may confound the relationship between media exposure and tobacco use as each variable was individually associated with mass media exposure (all Cramer's V ranged from 0.12 to 0.25 ), associated with tobacco use (all Cramer's V ranged from 0.06 to 0.13 ), but was not on the causal pathway between the predictor and outcome. This may explain the seemingly inverse relationship between being a Muslim and using tobacco and being Igbo and using tobacco present in bivariate analysis but reversed in direction in multivariable analysis. Future studies should fully explore the relationships between ethnicity, religion, socio-economic status, and tobacco use given Nigeria's diverse cultural and religious beliefs and, especially, as Nigeria's economy is projected to continuously grow [38].

This study has several limitations and strengths. The cross sectional nature precludes temporal ordering of the variables examined. There are possible spurious associations and potential confounders that were not explored. NDHS, conducted to explore maternal and child reproductive health, excluded older adults which may bias our 
study findings if, for example, old age is strongly associated with tobacco use. Last, in NDHS, questions about mass media exposure were not tailored to mirror specific advertising and marketing activities of tobacco companies. Questions that could directly link exposure to specific radio or television channels or programs or recall of tobacco insignia would have provided better evidence that exposure to mass media outlets, recall of tobacco products, and tobacco consumption are indeed related [39]. Notwithstanding these limitations, this study is a robust exploration of the various types of tobacco use among Nigerian adults using a nationally representative dataset where the multistage sampling features permits generalizability of findings to Nigerian adults. As such, this study can help to provide information for public health strategies that can adequately and efficiently address significant determinants of tobacco use, especially among Nigerian men. This study adds to the literature by assessing and documenting the extent to which various types of mass media outlet influence tobacco use in Nigeria before ratification of Nigeria's National Tobacco Control Bill. Future studies should continue to assess the different social patterns of tobacco use in Nigeria, particularly as its mass media channels, for example the movieproducing "Nollywood", continue to increase and as tobacco companies continue to segment the population to target and recruit new smokers.

Acknowledgments The authors would like to acknowledge the initiative for maximizing diversity program at the Harvard School of Public Health, the respondents and administrators of the NDHS 2008, and the anonymous reviewers of this manuscript.

Conflict of interest The authors declare that they have no conflict of interest.

\section{References}

1. Baris E, Bridgen LW, Prindiville J et al (2000) Research priorities for tobacco control in developing countries: a regional approach to a global consultative process. Tob Control 9:217-223

2. Yach D, Bettcher D (2000) Globalization of tobacco industry influence and new global responses. Tob Control 9:206-216

3. Oluwafemi A (2003) Regional summary for the African region. In: Shafey O, Dolwick S, Guidon GE (eds) Tobacco control country profiles, 2nd edn. American Cancer Society, Atlanta, pp 27-31

4. World Bank (2009) http://web.worldbank.org/WBSITE/EXTER NAL/COUNTRIES/AFRICAEXT/NIGERIAEXTN/0menuPK: $368906 \sim$ pagePK: $141132 \sim$ piPK:141107 theSitePK:36889600. html. Accessed 6 Mar 2010

5. National Population Commission (NPC) [Nigeria] and ICF Macro (2009) Nigeria demographic and health survey 2008. National Population Commission and ICF Macro, Abuja

6. World Health Organization Framework Convention on Tobacco Control (2005) http://www.who.int/fctc/signatories_parties/en/ index.html. Accessed 16 Oct 2009
7. BAT (1991) TMD. Bates no: 301750937-301750938 at http:// legacy.library.ucsf.edu/tid/dbf97a99/pdf?search=\%22301750937 $\% 20$ nigeria\% 22

8. BAT (1993) Awareness and image monitor-Nigeria: research proposals II. Bates no: 500108814-500108821 at http://legacy. library.ucsf.edu/tid/vyl76a99/pdf?search=\%22radio\%20tobacco $\% 20$ nigeria\% 22

9. National Cancer Institute (2008) The role of the media in promoting and reducing tobacco use. Tobacco control monograph no. 19. NIH pub. no. 07-6242. US Department of Health and Human Services, National Institutes of Health, National Cancer Institute, Bethesda, MD, USA

10. Song AV, Ling PM, Neilands TB, Glantz SA (2007) Smoking in movies and increased smoking among young adults. Am J Prev Med 33:396-403

11. Viswanath K, Ackerson L, Sorenson G et al (2010) Movies and TV influence tobacco use in India: findings from a national survey. Plos One 5(6):e11365

12. Owusu-Dabo E, Lewis S, McNeill A, Gilmore A, Britton J (2009) Smoking uptake and prevalence in Ghana. Tob Control 18: 365-370

13. Williams CT, Grier SA, Marks AS (2008) "Coming to town": the impact of urbanicity, cigarette advertising, and network norms on the smoking attitudes of black women in Cape Town, South Africa. J Urban Health 85(4):472-485

14. Islam SMS, Johnson CA (2007) Western media's influence on Egyptian adolescent's smoking behavior: the mediating role of positive beliefs about smoking. Nicotine Tob Res 9(1):57-64

15. Shah BS, Pednekar MS, Gupta PC (2008) The relationship between tobacco advertisements and smoking status of youth in India. Asian Pac J Cancer Prev 9:637-642

16. BAT (1996) JPGL relaunch brief: Nigeria. Bates no: 800520464/ 0465 at http://legacy.library.ucsf.edu/tid/toc73a99/pdf?search= $\% 22$ radio\%20tobacco\%20nigeria\% 22

17. BAT (1993) Benson and Hedges golden tones. Bates no: 503649 543-503649544 at http://legacy.library.ucsf.edu/tid/esy45a99/pdf? search $=\% 22$ turn $\% 20$ to $\% 20$ gold $\% 20$ nigeria $\% 22$

18. BAT (1994) Golden tones manual: draft 1. Bates no: 500273303-500 273345 at http://legacy.library.ucsf.edu/tid/jjn70a99/pdf?search=\% $22500273345 \% 20$ nigeria\%22

19. BAT Radio script. Bates no: 700555627-700555632 at http:// legacy.library.ucsf.edu/tid/cqb70a99/pdf?search=\%22turn\%20to\% 20gold\%20nigeria\% 22

20. Peer N, Bradshaw D, Laubscher R, Steyn K (2003) Trends in adult tobacco use from two South African demographic and health surveys conducted in 1998 and 2003. SAMJ 99(10): 744-749

21. Mackay J (1994) The fight against tobacco in developing countries. Tuber Lung Dis 75:8-24

22. Obot I (1990) The use of tobacco products among Nigerian adults: a general population survey. Drug Alcohol Depend 1990(26):203-208

23. Gupta PC, Ray CS (2003) Smokeless tobacco and health in India and South Asia. Respirology 8:419-431

24. Ima-Obong AE (2008) Global youth tobacco survey for Nigeria. Centers for Disease Control. http://www.afro.who.int/dnc/data bases/gyts/reports/NIGERIA_GYTS\%202008.pdf. Accessed 16 Oct 2009

25. Patel P, Okechukwu CA, Collin J, Hughes B (2009) Bringing 'light, life and happiness': British American tobacco and music sponsorship in Sub-Saharan Africa. Third World Q 30(40): 685-700

26. Drope J (2011) Nigerian tobacco situation analysis. http://www. africatobaccocontrol.org/en/images/resource_library/ATSA\%20 Nigeria\%20Synthesis.pdf. Accessed 29 Dec 2011 
27. Euromonitor (2009). http://www.euromonitor.com/Tobacco_in_ Nigeria. Accessed 24 Jan 2011

28. McNutt LA, Holcomb JP, Carlson BE (2000) Logistic regression analysis: when the odds ratio does not work: an example using intimate partner violence data? J Interpers Violence 15:1050-1059

29. World Health Organization (2010) http://www.who.int/tobacco/ surveillance/policy/country_profile/nga.pdf. Accessed 29 Dec 2011

30. Fawibe AE, Shittu AO (2011) Prevalence and characteristics of cigarettes smokers among undergraduates of the University of Ilorin, Nigeria. Niger J Clin Pract 14(2):201-205

31. Adebiyi AO, Faseru B, Sangowawa AO, Owoaje ET (2010) Tobacco use amongst out of school adolescents in a local government area in Nigeria. Subst Abuse Treat Prev Policy 5:24

32. Gureje O, Degenhardt L, Olley B et al (2007) A descriptive epidemiology of substance use and substance abuse disorders in Nigeria during early twenty-first century. Drug Alcohol Depend 91:1-9

33. Pampel F (2008) Tobacco use in Sub-Saharan Africa: estimates from the demographic health surveys. Soc Sci Med 66: $1772-1783$

34. Lopez AD, Collishaw NE, Piha T (1994) A descriptive model of the cigarette epidemic in developed countries. Tob Control $3(3): 242-247$
35. Rudatsikira E, Muula AS, Siziya S (2010) Current use of smokeless tobacco among adolescents in the Republic of Congo. BMC Public Health 10:16

36. Nielsen (2008) Average US home now receives a record 118.6 TV channels, according to Nielsen. http://en-us.nielsen.com/ content/dam/nielsen/en_us/documents/pdf/Press \%20Releases/ 2008/June/Average $\% 20$ US\% 20 Home $\% 20$ Now\%20Receives $\%$ 20a\%20Record\%20118.6\%20TV\%20Channels,\%20According $\% 20$ to\%20Nielsen.pdf. Accessed 17 Aug 2010

37. Eraction (2008) http://www.eraction.org/publications/eraction jan_2008.pdf. Accessed 25 Jan 2011

38. McKinsey Global Institute (2010) Lions on the move: the progress and potential of African economies. http://ww1.mckinsey. com/mgi/publications/progress_and_potential_of_african_econo mies/pdfs/MGI_african_economies_full_report.pdf. Accessed 29 Dec 2011

39. Blake KD, Viswanath K, Blendon R et al (2010) The role of reported tobacco-specific media exposure on adult attitudes towards proposed policies to limit the portrayal of smoking in movies. Tob Control 19:191-196 